\title{
Exploring Diversity Management in Transnational Corporations Through the Lens of Migration and Expatriation
}

\author{
Kingsley U. Utam, MSc
}

University of Bradford, Bradford, United Kingdom

(iD) https://orcid.org/0000-0003-2586-1571

Uduak Archibong, $\mathrm{PhD}$

University of Bradford, Bradford, United Kingdom

(iD https://orcid.org/0000-0001-7146-0395

Sean Walton, $\mathrm{PhD}$

University of Huddersfield, Huddersfield, United Kingdom

(iD https://orcid.org/0000-0002-0645-894X

Cyril Eshareturi, PhD

University of Bradford, Bradford, United Kingdom

(iD) https://orcid.org/0000-0002-3770-0612

Contact: k.u.utam@bradford.ac.uk

\section{Abstract}

In this study, we aim to develop an understanding of the similarity between migration and expatriation, identify both as elements in diversity, and draw attention to the additional layer of ethnic diversity created by the high number of top management expatriates in some Nigerian subsidiaries of transnational corporations. Using the qualitative research design, we thematically analysed data from semistructured interviews with six indigenous managers in four transnational corporations. We found a significant number of expatriate managers in two subsidiaries and a lack of diversity management framework to address the new layer of diversity as reflected in the unequal treatment of indigenous managers. We conclude that migration and expatriation are similar and could be better managed through effective diversity management framework.

Keywords: migration; transnational migration; expatriation; diversity and inclusion; ethnic diversity; transnational corporations

Date Submitted: December 13, 2018 | Date Published: May 27, 2020

\section{Recommended Citation}

Utam, K. U., Archibong, U., Walton, S., \& Eshareturi, C. (2020). Exploring diversity management in transnational corporations through the lens of migration and expatriation. Journal of Social Change, 12, 71-86. https://doi.org/10.5590/JOSC.2020.12.1.06 
Utam et al., 2020

\section{Introduction}

Modern societies have witnessed a significant change in ethnic configuration in the last few decades as a direct consequence of migration (Bove \& Elia, 2017). The ensuing ethnic diversity is noticeable in all facets of society especially in formal organizational settings, which are even more diverse today as a result of globalization and the ease of labor movement across international borders. These events have left no doubt in the minds of observers that migration deserves more attention from scholars and practitioners. The literature on migration has, however, narrowly focused on cross border movement from developing to industrialized countries and neglected the reverse movement. It has also paid more attention to the socioeconomic backgrounds of the movers; the political, economic, and social conditions in their home countries; their demographic characteristics and the motive for movement instead of the phenomenon of movement itself (Baruch et al., 2013; Berry \& Bell, 2012; Naude, 2008).

The United Nations (1998) defined international migrants as people who change their countries of usual residence. Similarly, the International Organization for Migration (2016) defined migrants as individuals who have or are in the process of moving across local or international borders away from their usual places of residence irrespective of legal status, nature of movement (voluntary or involuntary), causes for movement, or duration of stay. International migration, therefore, is the physical movement from one geographical location to another across national boundaries (Andresen et al., 2014). Contemporary events in migration studies indicate that the field is continuously evolving in such a way that the traditional terminologies and typologies of migrants, destinations or outcomes are no longer applicable due to the constant change in form, direction, shape, and content of migration (O'Reilly, 2012). Migration in the modern world is characterized by "geographical fluidity" and constant movements as opposed to population shifts and one-off events (O’Reilly, 2012). De Haas (2005) explained that the use of contrasting terminologies such as "origin" or "destination" and categories such as "permanent," "temporary," and "return" migration to describe elements of migration represents the assimilationist and modernist political construct of the nation-state and citizenship. This model of migration has been challenged as the lives of immigrants in the modern world are now characterized by circulation and simultaneous attachment to multiple countries or societies (De Haas, 2010). These developments have fostered a shift in the traditional migration theory to what is today known as transnational migration theory.

Theoretically, the perception of migration has changed over the years. Earlier debates focused on "how to make Americans out of newcomers" (Levitt \& Jaworsky, 2007). This perspective, together with other assimilationist theories suggest that migrants tend to achieve socioeconomic equality with the native-born over time and that both migrants and natives experience transformation along the way as ethnicity and religion come into play (Kivisto, 2015; Levitt \& Jaworsky, 2007). The transnational migration theory holds that while migrants are integrated into the receiving societies, they simultaneously maintain firm commitments with their countries of origin (De Haas, 2010; Tsuda, 2012). Contrary to the view that considers migration as a permanent movement, the majority of migration is temporary as there are always interactions between migrants and their networks in the countries of origin, and many migrants eventually return to their home countries (Dustmann \& Weiss, 2007). Consequently, the assumption that migrants gradually relinquish their ties with home countries as they integrate into the receiving country leading to a drain in the available human capital of the home country is disproved (De Haas, 2010).

The transnational migration process involves migrants maintaining ties with their societies of origin simultaneously as they are integrated into the receiving country. This is achieved through remittance of money and ideas, holiday visits, telephone and internet communication, and pendular migration patterns (De Haas, 2010). Migrants now work, pray, and maintain political interest in multiple contexts, to the extent that 
some plant their roots in the host country, keep firm ties with their homeland, as well as become members of religious and political movements across the globe (Levitt, 2004). They can maintain networks that impact on their social relationships, patterns of economic exchanges, political mobilization, cultural identities, modes of information transfer, and the manner of professional associations (Vertovec, 2002). Not only are migrants changed in the transnational migration process, those that remain behind also change as they become exposed to migrants' social networks; and benefit from remittances and exchange of ideas, practices and the identities that migrants transmit (Levitt, 2004). Hence, even those who have never left their places of birth become part of the transnational operations as some of them adopt life-changing values and beliefs from across the world through contacts with transnational organizations (Levitt, 2004).

This new transnational migration framework should not be viewed as the opposite of the older assimilation theory. Instead, Bradatan et al. (2010) suggested that they should be seen as "complementary or successive stages" in the life of a migrant (the life course approach). The life course approach to migration contends that migrants tend to maintain transnational ties earlier on as they arrive at their destinations but become more assimilated as time goes on. Also, the second-generation migrants become even more integrated as they gain only a superficial knowledge of culture and language of their parent's countries of origin (Bradatan et al., 2010).

Transnational migration infrastructures facilitate the flow of migrants across locations. Migration infrastructures are institutions, technologies, and actors that are systematically interlinked to lubricate mobility (Lin et al., 2017; Xiang \& Lindquist, 2014). In short, they are sociotechnical enablers of mobility (Larkin, 2013). Xiang and Lindquist (2014) suggested that focusing on the infrastructure of transnational migration provides an alternative means of conceptualising migration instead of depending solely on the labor market, state policies or the social networks' explanation. Although infrastructures have eased international migration, they have also made the process more complicated. For instance, Xiang and Lindquist (2014) observed that while it has become faster and safer for Asian migrants to legally access job opportunities overseas, the process has also become more cumbersome. The complications in the international migration process are largely due to the involvement of nonmigrant players and the increasing level of regulations that have contributed to higher costs of migration (Xiang \& Lindquist, 2014).

Lindquist and Xiang (2018) also argued that the emerging trends in migration could be accounted for by sociotechnical factors shaping migration, leading to massive improvements in transportation, communication and surveillance. Some of these factors include the advances in telecommunication, development of biometric technology, and deregulation of the airline sector (Robinson, 2005), increasing involvement of commercial middlemen, and e-governance mechanisms. Government regulations are now infrastructural as they are not only used as a means of controlling the flow of immigrants or setting selection criteria but also deployed to integrate guarantors and employers. The infrastructures also encompass entering into bilateral agreements between the sending and destination countries, public-private partnerships and the development of transnational cooperation (Lindquist \& Xiang, 2018).

Furthermore, Schiller (2009) noted that many organizations have seized the opportunity of transnational migration to conduct big businesses as even the U.K. Postal Services have delved into the money transfer operations to facilitate migrants ability to send money back home to family and friends as well as for investment purposes. Some banks also give mortgages to migrants to develop properties in their home countries. Migrant remittances, investments and acquisition of expensive products have been on the rise in recent years (Ellerman, 2003; Schiller, 2009). World Bank (2006) described migrant remitters as agents of international development. Hence, as a part of the transnational process that reorganizes societies, migrant remittances may contribute to restructuring social relations (Schiller, 2009). 
However, migrant remittances could be said to produce both positive and negative effects in the societies of origin. Although remittances are acknowledged to contribute to improving the economic prospects of receiving countries, they also lead to social inequalities in home communities (Curran \& Saguy, 2001; Levitt \& Jaworsky, 2007). As well as serving as platforms for transmitting information, migration networks are also instrumental in the transfer of values and cultural perceptions (Curran \& Saguy, 2001). On the other hand, migration could engender a considerable level of surface-level social change in the receiving societies; involving changes to "economic organisations, role expectations, or norms" (Portes, 2010, p. 1544). It could also impact the deeper levels in terms of "the culture and the transformation of the value system, the social structure and the distribution of power" (p. 1544).

The transnational migration theory has a direct linkage with the transnational network of skilled migrants in a phenomenon regarded as expatriation. Vertovec (2002) suggested that skilled migrants form a transnational network and are characterized not only by binational movements but also by an international circulation. This goes to negate the earlier assumption about the migration of skilled individuals as an avenue for brain-drain. Brain-drain is characterized by the movement of highly skilled workforce from developing to industrialized countries with resultant loss of economic potential to the developing country (Dumont \& Lemaître, 2005; Lowell \& Findlay, 2001). In recent times the notion of brain-drain has been replaced with that of "globalisation of human capital, brain exchange, brain circulation and the creation of a globally mobile workforce" (Vertovec, 2002, p. 7). Thus, the network of skilled expatriates with strong ties in their countries of origin have been recognized as vital to the development of the sending countries without physical temporary or permanent return (Vertovec, 2002).

Okeja (2017b) traced the etymology of expatriate to the phrase ex Patria, which means the act of leaving one's country. From the etymology of the word itself, expatriation could be considered to mean an array of movements from one's country of origin to another because what is of significance is the act of movement rather than the reason for movement (Okeja, 2017b). An expatriate is a highly skilled migrant (Gatti, 2009). Hence, countries experience difficulties in defining those to be categorized as immigrants, resulting in the inadequacy of available migration data (Dumont \& Lemaître, 2005). Rather than focusing on the phenomenon of movement, the literature on expatriation and international management has focused on the motive for movement and the socioeconomic backgrounds of the movers instead of the phenomenon of the transnational movement (Bolino, 2007).

Given these narratives, the distinction between the migrant and the expatriate in the literature could be seen as unjust as it overstates the differences between the two terminologies and separates them into distinct fields of endeavor. The literature on international mobility has largely approached the issue from a narrow perspective, considering only the direction of labor flow-from developing to more developed countries and crucially, constructing Western countries as recipients of migrants (Gheasi \& Nijkamp, 2017; Lowell \& Findlay, 2001; Okeja, 2017b). However, Okeja (2017b) drew attention to what he termed "reversed migration," a situation where there is a reverse movement of people from Western countries to developing countries. This situation is prompted by improving economic conditions and opportunities in developing countries (Okeja, 2017b). Dustmann and Weiss (2007) argued that return migration could be of benefit to the home countries as migrants have acquired experiences from overseas which they could apply to their home country thus reversing the trend to brain-gain (Ellerman, 2003). This represents a more effective avenue for knowledge transfer, and that returning expatriates are better positioned to do this due to their vast knowledge and understanding of the local culture as opposed to foreign expatriates (World Bank, 2006). Hence, transnational migration tends to benefit both receiving and sending country as migrants potentially add value to both societies. 
Migration studies and diversity management have in the past been studied as distinct disciplines (Pilati et al., 2015). Migration management refers to strategies designed to handle issues relating to increased mobility of people across international borders. Diversity management, on the other hand, refers to approaches for dealing with a variety of differences, including gender, ethnicity, age, and sexuality (De Jong, 2016). While diversity is found to be inherent in pluralistic societies such as Nigeria (Mustapha, 2007), it is seen to be a consequent of migration in homogeneous societies like South Korea (Moon, 2015). Hence, it could be said that migration leads to diversity in some cases. For multicultural societies, an increase in immigration could further increase the layers of ethnic diversity as people of foreign ethnic origins move in and settle there either as highly skilled professionals sent from the headquarters of a transnational organization or individual independently searching for better job opportunities or as people seeking refuge from adverse sociopolitical and economic conditions.

Pilati et al. (2015) noted that the global workforce has become significantly more diverse in the last 2 decades as a result of increased migration flows. Therefore, migration has become a priority in the policy agenda of many countries due to factors relating to labor market integration, labor and skills shortages, perception of work competition between migrants and local job seekers and the impact of the economic recession of 2008 on migrant workers. Similarly, Bove and Elia (2017) asserted that migrants' prospects to carry with them an array of new skills and experiences as they move from one country to another have the potential to speed up the development of new technological innovation and economic development in the receiving countries. Conversely, the heterogeneity of workers may create communication barriers, coordination difficulties and destabilize social cohesion due to differences in race/ethnicity, religion, language, and other social characteristics of migrants if the enabling social and political conditions are not present or created for effective integration (Bove \& Elia, 2017; Pilati et al., 2015).

Migration and its relationship with diversity and diversity management have received some attention in recent times. The literature on diversity and migration has both points of convergence and divergence (Pilati et al., 2015). Areas of convergence centre on the institutional context, in that both fields consider issues of integration, discrimination and marginalization and opportunities for migrants. From the perspective of intergroup relations, the two fields show both similarities and distinctions. They are similar in the sense that both pay attention to issues relating to vulnerability and exploitation of intergroup relations (Pilati et al., 2015). On the other hand, the diversity literature goes further to consider hostile attitudes and discrimination against migrants. While the literature on migration extends to sending and receiving country perspective in terms of the brain drain/brain gain analysis and contention for available jobs by natives and migrants, and dependence on migrants for workforce balance by industrialized countries (Pilati et al., 2015). De Jong (2016) noted that migration and diversity are mostly discussed in relation to Western societies of the global North, and that diversity management is usually offered as a rational solution to the problems of ethnic pluralism in Western societies.

Scheible (2015) suggested that immigration is needed to balance the labor supply of industrialized countries. Transnational mobility has also become a very potent instrument in international organizations, and it is captured in a phenomenon known as expatriation in international management literature. Expatriation increases the level of the ethnic and cultural diversity of both work teams and the societies in general (Scheible, 2017). Research has found positive effects of expatriation on organizational development and international cooperation in a multinational organization (Scheible, 2015). It has also been noted that the literature has mostly neglected to recognize expatriation as an element in diversity management; that there has been no attempt to integrate expatriation and diversity management, as well as a lack of comprehensive diversity management approach that encompasses expatriation management (Scheible, 2015). These findings 
indicate that diversity and expatriation have been studied as if they were mutually exclusive, and underscores the need for a more integrated approach to understanding the linkages between the two concepts.

Transnational corporations send home-country staff and specialist executives to foreign subsidiaries for a variety of reasons. Some of these reasons include effecting control; transferring skills, knowledge, managerial and technical knowhow; ensuring that the subsidiaries conform to corporate culture and global strategy; organizational development, and to ensure that subsidiary operations are in the best interest of the global headquarters (Bolino, 2007; Dumont \& Lemaître, 2005; Harzing, 2001; Oltra et al., 2013; Syed et al., 2014). Scheible (2015) argued that because the knowledge and experiences of different individuals are needed across all locations to enhance organizational development, it becomes imperative to consider managing the diversity that would emerge as a result of staff mobility. This, together with the widely accepted business case for diversity which argues that the proper management of differences in organizations can create competitive advantage through learning and improvements in creativity underscores the need for deliberate management of expatriation (Scheible, 2015).

Depending on the number of expatriates and foreign nationals in a subsidiary, there is a tendency for a significant cultural and ethnic dilution of the workforce of the local subsidiary. Reitz (2002) explained that this situation could lead to a departure from the assimilationist ideology and introduce an era where assimilation becomes meaningless and there may no longer be a clear majority ethnic group. Therefore, it may be more meaningful to refer to the various forms of diversity that arise as a result of transnational immigration. Faist (2009) suggested that transnationality is a novel and a new form of diversity. He also suggested that not only does diversity address migrant incorporation, it also addresses the way societies and organizations handle multiculturalism. Consistently, it is acknowledged that expatriation is an element of migration that has been found to enhance diversity in transnational companies (Černek \& Maková, 2013; Scheible, 2015). Unfortunately, the sparse literature available has so far focused on the migration of people from developing to developed countries and has almost completely neglected the reverse direction of movement from developed to developing countries. This further compounds the problems of ethnic diversity, particularly in multiethnic societies such as Nigeria.

Nigeria is a multiethnic country and ranks 18th in the world (Wee, 2018), and 16th in sub-Saharan Africa in terms of ethnic and cultural diversity (Fearon, 2003). There are conflicting reports as to the number of ethnic groups in the country. However, Adeleye et al. (2014) put the figure at between 250 to 400 distinct ethnic, linguistic, religious, and cultural groups, comprising three major ethnic groups and several other smaller groups. The major ethnic groups include Hausa/Fulani, Yoruba, and Igbo, whereas other smaller groups comprise Efik Ibibio, Tiv, Ijaw, Itsekiri, Urhobo, Bini, and a host of others. Despite this vast diversity, Adeleye et al. (2014) further noted the absence of a legal and institutional framework for managing ethnic diversity. This creates an environment where discrimination and inequality have eaten deep into both public and private sectors of the Nigerian economy (Adeleye et al., 2014; Langer et al., 2009). As one of the most ethnically diverse countries in the world, Nigerian subsidiaries of transnational companies are confronted with the risk of managing a wide range of ethnic diversity (Adeleye et al., 2012). With the addition of a significant number of foreign nationals (expatriates), there is a likelihood of the emergence of another layer of diversity, particularly at the top management level.

There is a significant movement of expatriate managers from headquarters in developed countries to subsidiaries in developing countries for the reasons advanced above (Shrestha, 2011). Further, it has been argued that the process of expatriation management involving knowledge management, unveiling new perspectives, and team enrichment are considered robust instruments for diversity management (Scheible, 2015). Unfortunately, the literature on both diversity and expatriation management has not addressed the possibility of incorporating diversity management strategies into the administration of the expatriation 
process in international companies (Scheible, 2015). Hence, we aim to bridge the gaps identified above by developing an understanding of the similarity between migration and expatriation and to identify the two concepts as elements in diversity management. We also aim to create knowledge and understanding of the additional layer of diversity created by top management expatriates in transnational corporations operating in a multiethnic developing country (Nigeria). Hence, we hope to explore the link between migration and expatriation and demonstrate that these phenomena can create an additional layer of ethnic diversity in transnational corporations with subsidiaries in a multiethnic society.

\section{Method}

In this study, we report a part of the findings of a doctoral study on ethnic diversity and inclusion in transnational corporations in Nigeria. We adopt a qualitative research design for the collection and analysis of data. The data used was obtained through a primary source using the semistructured interview method, which is a nonstandardized interview method used in gathering qualitative data (Gray, 2014). This method is ideal as it enables an in-depth probe of the responses provided by the participants (Bryman, 2015). Also, this data collection method enabled the interviewees to share their knowledge and experiences on other issues related to the objectives of the study. Semistructured interviews were conducted with six local/indigenous top managers in four transnational companies.

The interviews were conducted via telephone as the interviewees preferred this option due to its costeffectiveness, flexibility and time-saving advantages (Gray, 2014). A semistructured interview guide was used for all interviewees. The interview questions covered a variety of issues including the number or percentage of expatriates in top management positions and the organization, the importance of diversity and inclusion, ethnic diversity and inclusion policies and practices, structures put in place for managing expatriation process, human resource-related activities, and the mechanisms for managing local expatriate mix. All interviews were recorded in MP3 formats using portable digital audio recorders attached to the telephone.

All the recorded interviews were transcribed by the lead researcher and saved in a secure password-protected personal laptop computer. The transcripts were read several times to acquaint the researcher with the data and coding was done inductively. The thematic analysis method was used to analyse the data. The analysis involves the identification, analysis and reporting of patterns and themes within a qualitative data (Braun \& Clarke, 2006). One of the merits of adopting thematic analysis is its flexibility and the relative ease with which the method is applied in conducting qualitative data analysis (Braun \& Clarke, 2006).

The six indigenous top managers interviewed were from four transnational organizations representing three sectors of the Nigerian economy: pharmaceuticals, fast-moving consumer goods (FMCG) and the oil and gas sectors. The four organizations consist of one pharmaceutical, two FMCGs and one oil and gas company. The healthcare company (HC) is a Swiss-based transnational corporation with operations in more than 100 countries and employs over 90,000 workers around the world. It has no manufacturing presence in Nigeria and operates as a diagnostic and pharmaceutical products company with about 120 employees in the local subsidiary. The first FMCG company (FMCG1) is one of the largest food and beverage companies in Africa. It has operated in Nigeria for over 57 years with staff strength of over 2,300 direct employees. It has three manufacturing sites, eight branch offices, and a head office located in Lagos. The second FMCG company (FMCG2) has its headquarters in the United Kingdom with a considerable manufacturing presence in Nigeria. It has been in operation for over 100 years and currently employs over 3,500 workers across the country. The oil and gas company (OandG) has operated in Nigeria for over 40 years. The company's assets include land, swamp, and near-shore concessions spanning over 3,000,000 acres, and it has over 2,000 staff in Nigeria. 
Table 1. Characteristics of interviewees

\begin{tabular}{|c|c|c|c|c|c|c|}
\hline $\begin{array}{l}\text { Interviewee } \\
\text { pseudonym }\end{array}$ & Gender & $\begin{array}{c}\text { Years at } \\
\text { organization }\end{array}$ & Department & Industry & $\begin{array}{c}\text { Company } \\
\text { pseudonym }\end{array}$ & $\begin{array}{c}\text { Locatio } \\
\text { n }\end{array}$ \\
\hline Bisi & Female & 9 & $\begin{array}{c}\text { Market and Safety } \\
\text { Accounts and } \\
\text { Governmental Affairs }\end{array}$ & $\begin{array}{l}\text { Healthcare } \\
\text { (HC) }\end{array}$ & $\mathrm{HC}$ & Lagos \\
\hline Ese & Female & 5 & $\begin{array}{l}\text { Corporate } \\
\text { Communications }\end{array}$ & $\mathrm{HC}$ & $\mathrm{HC}$ & Lagos \\
\hline Musa & Male & 15 & $\begin{array}{c}\text { Corporate } \\
\text { Communications }\end{array}$ & $\begin{array}{l}\text { Fast-moving } \\
\text { consumer } \\
\text { goods (FMCG) }\end{array}$ & FMCG1 & Abuja \\
\hline Chika & Male & 10 & Human Resources & FMCG & FMCG2 & Lagos \\
\hline Akinjide & Male & 6 & Branch Head & FMCG & FMCG1 & Ogun \\
\hline Udo & Male & 16 & Human Resources & Oil and gas & OandG & Lagos \\
\hline
\end{tabular}

Full ethical approval was granted for the conduct of this study by the Chair of the Humanities, Social and Health Sciences Research Ethics at the University of Bradford on October 4, 2017.

\section{Findings}

Managers were asked to speak about the importance of diversity and inclusion in their organizations. The responses were very revealing as some of the managers referred to the global nature of their organizations, which makes diversity an integral part of the employee management strategy. For instance, one of them (Musa) described the organization as being globally managed, making it possible to relate with talents from different countries of the world and enhancing the ease of mobility of employees across different business operations and locations. Thus, by the nature of their business operations, expatriation and diversity management are essential and integral elements in promoting efficiency within the organization. Musa's description highlights the importance of cross-country mobility of talents as a way of embracing diversity and the critical role it plays to organizational success.

The participants were also asked to highlight some of the initiatives have adopted by their organizations to foster diversity and inclusion. Musa's list of initiatives included expatriation and mission. Incidentally, these two initiatives involve mobility of workers from one location to another across national boundaries. He revealed that the initiatives were mostly available to senior employee categories and were also very important for career growth and success. He also added that the more mobile employees are, the better their prospects of career advancement.

...mobility is your ability to move to to...; it is your openness to be transferred outside of your place of comfort, ok? So the organization rates mobility as a strong factor for career success. So people who are successful in their careers in this organization actually are people who have indicated that they are mobile. And generally in getting you up the ladder, they actually 'first of all move you, so they can send you on mission, mission is something that allows you to work outside of your own country for a short period of time. So that is used to enhance diversity.

Interestingly, Musa's organization recognized expatriation as a factor that enhances diversity. According to him, employees that are expatriated are those that have been identified as talents and possess the competence and skills to contribute to the company's business across the world and such employees may not be redeployed back to their home country until they leave the organization. 
During the interview, Musa made reference to two layers of diversity that exist in his organizationinternational and local. In his view, the employees had knowledge of local diversity but were not familiar with what he referred to as global diversity. In his words, “...however, in the Nigerian environment, you know, as much as it is social feels that local inclusion is okay, but international inclusion is not what we are very much used to.”

Musa also revealed that there are many expatriates in senior management positions in the subsidiary and that the number of indigenous managers decreased as you move upwards in the organizational hierarchy. According to him, this may be due to the organization's desire to control the activities and avoid possible bias and collusion among people from the same country.

Musa's comments about the significant number of expatriates in top management positions were shared by Akinjide, a manager in the same company. According to him, the percentage of expatriates to local managers is $60-40 \%$. Chika also noted that about $40 \%$ of top management staff in FMCG2 were expatriates or foreign nationals. The number of expatriate managers was much lower in OandG, although Udo was not sure about the exact percentages; he said that expatriates should be about $10 \%$ of the total number of managers. However, this is in contrast with the healthcare company where, as Bisi noted, there were no expatriates or foreign managers in the local subsidiary.

To investigate whether organizations recognize the diversity created by expatriation and the efforts they were making to blend this layer of diversity to overall organizational diversity strategy, the researcher asked managers in companies with expatriates what they are doing in this regard. Udo explained that the occurrence of the two layers of diversity leaves his organization no choice than to try to derive the full benefits it affords. He stated that the blending of the two occurs by understanding the corporate values devoted to diversity and reflecting it in their business operations. He also said that his organization takes steps to operate within the antidiscrimination laws of the country. Chika explained that the first step his organization takes to ensure that expatriates are well integrated into the system is through a structured induction programme and international assignment training. This begins long before the expatriate embarks on the assignment. The aim is to help them understand variations in culture, beliefs, values, food, and to give them ideas about the people they will work with at the foreign subsidiary.

Another interesting finding relates to the perceptions or experiences of discrimination among some respondents. For instance, even as managers, some of the respondents reported perceived discrimination against them. Chika believed that his request for management intervention in installing speed breakers on a federal road leading to one of his factories, on which several employees had lost their lives due to road accidents was ignored because neither he nor any of the victims were foreigners or expatriates. Chika said the situation was also noticed by the chairman of the Junior Staff Association (a junior staff union leader), an essential figure in the organization.

However, because of his managerial position and responsibilities, Chika felt the responsibility to protect the reputation of the organization; hence, he found it difficult to openly agree with with the chairman. He stated,

...now because of the role I play I didn't accept that in front of him, even though behind my mind I know that he is actually saying the truth if we had had an expatriate die on that road I can bet you within 2 or 3 days they would find something to do on that road.

Chika attempted to offer a justification for this preferential treatment in favor of expatriates from the perspective of the organization. He argued that because the expatriates were from a different country, part of the terms of their agreement with the company was that the company would be accountable not only to the 
expatriate but also to their family and government of their home countries. As a result, the organization always goes the extra mile to ensure their safety.

Musa recounted an event in the past when he felt discriminated against, although he would not admit the existence of discrimination in the organization to his subordinates. He reported feeling discriminated against during an international recruitment exercise in his organization because he obtained his educational qualifications from local universities. He believed a different candidate who obtained his academic qualifications from a foreign university got the job ahead of him even though he (Musa) was a better candidate in terms of experience. Chika noted that the systemic discrimination against local managers leads to a feeling of inferiority complex when comparing themselves with their foreign counterparts.

The above findings indicate the existence of a significant number of expatriates in senior management positions in some subsidiaries of transnational corporations in Nigeria. It shows ineffectiveness in the management of the additional layer of diversity created by top management expatriation. This is reflected in the frustration and dilemma faced by local managers in performing their duties. Some of the problems emanate from indigenous managers' urge to protect corporate image even when sometimes they become victims of systemic inequalities inherent in organizational processes.

\section{Discussion}

Our aim in this study was to explore the link between migration and expatriation and demonstrate that these phenomena can create an additional layer of ethnic diversity in transnational corporations with subsidiaries in a multiethnic society. Very few studies have considered expatriation and migration as elements in the diversity management process.

Findings from this study reveal a steep variation in the number of expatriate top managers in the four participating transnational companies. This ranges from $0 \%$ to $60 \%$ depending on the scope of operations in the subsidiary. The scope of operations here refers to whether the company manufactures its products in the local subsidiary. Evidence from this study suggests that subsidiaries with local manufacturing operations employ more expatriates than those without local manufacturing. Hence, the healthcare company which does not have local manufacturing capacity employs no expatriates in the Nigerian subsidiary because it does not need technical manufacturing expertise. Again, this finding is consistent with one of the reasons advanced for expatriation by Dumont and Lemaitre (2005) and Bolino (2007), because not much technical knowhow is required in this subsidiary, it makes sense not to engage expatriates in the Nigerian subsidiary.

We also found a substantial number of expatriates in top management positions in some of the subsidiaries to dilute the workforce and create an additional layer of top management ethnic diversity. With about $40 \%$ to $60 \%$ of management being expatriates in two of the participating organizations, there is a different layer of ethnic diversity created at this level which warrants the attention of experts and practitioners. Consistent with this finding, Kasinitz et al. (2009) acknowledged the capacity of migration to alter the ethnic structure of receiving cities or states. For instance, the United States, New York, in particular, comprises almost $60 \%$ of immigrants and their children. They further noted mass migration into the United States complicate the deeply rooted racial divisions (Kasinitz et al., 2009). Although mass migration has the potential of significantly changing the characteristics of a population, it is challenging to say the same about its ability to transform the culture and social structure of the receiving nation as a whole (Portes, 2012). 
Interestingly, one of the managers identified initiatives that relate to mobility across international borders as programmes that enhance diversity. This implies that the company attempts to promote organizational diversity globally by sending managers and professionals to foreign subsidiaries. Further, findings also reveal that only highly skilled and talented employees are sent on expatriate assignments. The above findings are consistent with the views of Bolino (2007) and Dumont and Lemaître (2005), who stated that transnational companies send expatriates to overseas subsidiaries partly to transfer skills, knowledge, managerial and technical knowhow.

Further, Syed et al. (2014) argued that the use of expatriates by transnational corporations may create a perception that expatriates dominate top management positions to the detriment of local employee career progression prospects. Expatriation practices may create "glass ceilings," which may hinder local employees' chances of attaining their full potentials, resulting in lower performance and possibly high turnover rates. Given this scenario, it is possible to argue that migration to developing countries in the form of expatriation tends to produce negative results if the ensuing diversity is not well managed. As expatriates dominate top management, power and control authority predominantly reside with them, thus creating a situation of imbalance between the locals and expatriates. This is consistent with the argument advanced by Okeja (2017a), which holds that one of the moral challenges of expatriation to developing countries hinges on the discretionary and unequal distribution of power amongst employees.

Findings in this study also indicate the existence of forms of discrimination against local managers. One manager felt he was not being listened to because of his status as a local manager, and because the issue he raised had not directly affected any foreign employee. Another felt that he was not given a job during an international recruitment exercise because he obtained his academic qualifications from local (Nigerian) universities. Al Ariss (2014) suggested that Western expatriates are allocated better senior positions in the United Arab Emirates when compared to other people from other cultures. This leads to a situation where locals feel dominated by expatriates in their own country; they feel threatened and concerned over prospects for career advancement as they perceive skilled expatriates as withholding knowledge from them (Al Ariss, 2014). Another manager revealed that although he had not directly experienced any form discrimination, he was aware it existed, but added that individuals perpetrated such practices on their own accord within the organization without the approval of management.

The frustration experienced by indigenous managers, who feel the responsibility for managing junior staff perception of unfair practices in the organization, even when they (indigenous managers) experience discrimination calls for attention as this may lead to job dissatisfaction and consequently, a fall in performance. The fact that these managers struggle to defend their organizations before junior employees reflect their loyalty, but at the same time, they owe it to the junior employees to be sincere in all issues. This is an indication of the lack of holistic diversity management strategy designed to create a culture of inclusion and equality. In this study, we argue that in the absence of such a strategic diversity management framework, perceived discrimination between expatriates and locals will persist, which has the potential to degenerate into tensions that could disrupt organizational activities. Such disruptions could markedly impact on employee performance productivity (Oltra et al., 2013; Toh \& DeNisi, 2005).

Local managers reported feeling inferior when compared with their foreign counterparts. This feeling of inferiority derives from systemic inequalities which tend to give undue advantage to expatriates. $\mathrm{Li}$ and Kleiner (2001) noted that this can lead to a situation where locals become dissatisfied and disillusioned and develop low morale as expatriates are perceived to be treated better. 
Finally, the above findings draw the attention of academics and practitioners in the field of diversity and expatriation to this additional layer particularly in a country characterized by a high level of ethnic diversity. There is a need to incorporate the management of this additional diversity layer into the overall global diversity strategy of organizations right from the headquarters of the transnational corporation. This could be possible by developing a robust and detailed global strategic diversity management framework that takes care of different national and cultural contexts.

\section{Conclusion}

It is important to consider both diversity and migration studies side by side as the meaning of both terms intersect (De Jong, 2016; Pilati et al., 2015). Indeed, incorporating diversity management into the discourse on migration management could enhance the understanding of the relationship between diversity and expatriation. Further, "migration" and "expatriation" have a shared meaning, which involves the movement of people across geographical boundaries. The terms have, over the years, been studied under separate disciplines as if they mean different things. This is because scholars and practitioners have, rather than focusing on the phenomenon itself, concentrated more on adjoining factors such as the motive for movement, the socioeconomic backgrounds, and the skills possessed by the movers.

Our literature findings have shown that migration and expatriation share a similar meaning. Furthermore, the movement of highly skilled workers to subsidiaries of transnational corporations can dilute the workforce and create an additional layer of ethnic diversity within an already diverse workforce as shown in two of our four participating organizations. There is a lack of comprehensive international strategic diversity management framework to manage the complications created by the extra layer of diversity. This became apparent as some local managers who had personal experiences of discrimination were confronted with the dilemma of managing local subordinates' perceptions of discriminatory practices within the organization. The new layer of diversity identified by this study calls for the development of new strategies for its management. Such strategies should be incorporated into the overall global diversity policies of the transnational corporations concerned. Thus, we suggest that specific set of diversity strategies be adopted for the management of indigenous ethnic diversity, and a different set of policies be developed for the management of local versus foreign employee mix. This is because the two layers are not the same and require different knowledge, skills and levels of cultural competencies for effective management.

Finally, we call for future research to shift attention from Western transnational corporations and focus on smaller international companies (for example, those with Chinese and Indian ownership) operating in other multicultural African countries. Such studies may focus on exploring organizational structures upon which expatriation and diversity are managed. Also, it could be instructive to consider how junior employees deconstruct the relationship between diversity and expatriation from a developing country perspective.

\section{Limitations}

The views used in this study were those of the host country managers only; thus, the findings cannot be generalized. It would have been more instructive to use a second perspective-the expatriate's viewpoint as well for more robust and nuanced analyses. This is because expatriates are at the centre of the study, and they interact with local employees, managers and other stakeholders. Consequently, their views could have provided a better understanding of the extent of the application of diversity management policies. Another limitation of this study is the number of interviews conducted. In light of this, it could be challenging to say here that the views of the six respondents represent those of the entire country. Notwithstanding, considering the dearth in research on the subject matter from the Nigerian context, the information in this study 
represents a starting point of a discourse that could trigger the interest of other researchers in the fields of migration, expatriation and diversity.

\section{References}

Adeleye, I., Aja-Nwachukwu, F., \& Fawehinmi, Y. (2012). Managing diversity in Nigeria: The Chevron way. Human Resource Management Journal: Journal of the CIPMN, 4(1), 1-13.

Adeleye, I., Atewologun, D., \& Matanmi, O. (2014). Equality, diversity and inclusion in Nigeria: Historical context and emerging issues. In International Handbook on Diversity Management at Work (pp. 195-216). Edward Elgar Publishing.

$\mathrm{Al}$ Ariss, A. (2014). Voicing experiences and perceptions of local managers: Expatriation in the Arab Gulf. The International Journal of Human Resource Management, 25(14), 1978-1994.

Andresen, M., Bergdolt, F., Margenfeld, J., \& Dickmann, M. (2014). Addressing international mobility confusion: Developing definitions and differentiations for self-initiated and assigned expatriates as well as migrants. The International Journal of Human Resource Management, 25(16), 2295-2318.

Baruch, Y., Dickmann, M., Altman, Y., \& Bournois, F. (2013). Exploring international work: Types and dimensions of global careers. The International Journal of Human Resource Management, 24(12), 2369-2393.

Berry, D. P., \& Bell, M. P. (2012). "Expatriates": Gender, race and class distinctions in international management. Gender, Work \& Organization, 19(1), 10-28.

Bolino, M. C. (2007). Expatriate assignments and intra-organizational career success: Implications for individuals and organizations. Journal of International Business Studies, 38(5), 819-835.

Bove, V., \& Elia, L. (2017). Migration, diversity, and economic growth. World Development, 89, 227-239.

Bradatan, C., Popan, A., \& Melton, R. (2010). Transnationality as a fluid social identity. Social Identities, 16(2), 169-178.

Braun, V., \& Clarke, V. (2006). Using thematic analysis in psychology. Qualitative research in psychology, 3(2), 77-101.

Bryman, A. (2015). Social research methods (5th ed.). Oxford University Press.

Černek, M., \& Maková, K. (2013). The issue of Asian origin expatriates as a part of the diversity management in the Moravian-Silesian region. https://pdfs.semanticscholar.org/a197/9334629f1daofa3d9063a6cf592bdbbffa14.pdf

Curran, S. R., \& Saguy, A. C. (2001). Migration and cultural change: a role for gender and social networks? Journal of International Women's Studies, 2(3), 54-77.

De Haas, H. (2005). International migration, remittances and development: Myths and facts. Third World Quarterly, 26(8), 1269-1284.

De Haas, H. (2010). Migration and development: A theoretical perspective International Migration Review, 44(1), 227-264.

De Jong, S. (2016). Converging logics? Managing migration and managing diversity. Journal of Ethnic and Migration Studies, 42(3), 341-358. 
Dumont, J.-C., \& Lemaître, G. (2005). Counting immigrants and expatriates in OECD countries: A new perspective (OECD Social, Employment, and Migration Working Papers, No. 25). OECD Publishing. https://doi.org/10.1787/521408252125

Dustmann, C., \& Weiss, Y. (2007). Return migration: theory and empirical evidence from the U.K. British Journal of Industrial Relations, 45(2), 236-256.

Ellerman, D. (2003). Policy research on migration and development. The World Bank.

Faist, T. (2009). Diversity: A new mode of incorporation? Ethnic and Racial Studies, 32(1), 171-190.

Fearon, J. D. (2003). Ethnic and cultural diversity by country. Journal of Economic Growth, 8(2), 195-222.

Gatti, E. (2009). Defining the Expat: the case of high-skilled migrants in Brussels. Brussels Studies. https://journals.openedition.org/brussels/681

Gheasi, M., \& Nijkamp, P. (2017). A brief overview of international migration motives and impacts, with specific reference to FDI. Economies, 5(3), 31.

Gray, D. E. (2014). Doing research in the real world. Sage.

Harzing, A.-W. (2001). Of bears, bumble-bees, and spiders: The role of expatriates in controlling foreign subsidiaries. Journal of World Business, 36(4), 366-379.

International Organization for Migration. (2016). Who is a migrant? https://www.iom.int/who-is-a-migrant

Kasinitz, P., Mollenkopf, J. H., Waters, M. C., \& Holdaway, J. (2009). Inheriting the city: The children of immigrants come of age. Russell Sage.

Kivisto, P. (2015). Incorporating diversity: Rethinking assimilation in a multicultural age. Routledge.

Langer, A., Mustapha, A. R., \& Stewart, F. (2009). Diversity and discord: Ethnicity, horizontal inequalities and conflict in Ghana and Nigeria. Journal of International Development, 21(4), 477-482.

Larkin, B. (2013). The politics and poetics of infrastructure. Annual Review Of Anthropology, 42, 327-343.

Levitt, P. (2004). Transnational migrants: When "home" means more than one country. Migration Information Source. https://www.migrationpolicy.org/article/transnational-migrants-when-homemeans-more-one-country

Levitt, P., \& Jaworsky, B. N. (2007). Transnational migration studies: Past developments and future trends. Annual Review of Sociology, 33, 129-156.

Li, L., \& Kleiner, B. H. (2001). Expatriate-local relationship and organisational effectiveness: A study of multinational companies in China. Management Research News, 24(3/4), 49-56.

Lin, W., Lindquist, J., Xiang, B., \& Yeoh, B. S. (2017). Migration infrastructures and the production of migrant mobilities. Mobilities, 12(2), 167-174.

Lindquist, J., \& Xiang, B. (2018). The infrastructural turn in Asian migration. In G. Liu-Farrer \& B. Yeoh (Eds.), Routledge handbook of Asian migrations (pp. 152-161). Routledge.

Lowell, B. L., \& Findlay, A. (2001). Migration of highly skilled persons from developing countries: impact and policy responses. International Migration Papers, 44, 25.

Moon, K. H. S. (2015). South Korea's demographic changes and their political impact (East Asia policy paper). https://www.brookings.edu/wp-content/uploads/2016/06/South-Koreas-demographicchanges-and-their-political-impact.pdf

Mustapha, A. R. (2007). Institutionalising ethnic representation: How effective is the Federal Character Commission in Nigeria? Centre for Research on Inequality, Human Security and Ethnicity. 
Naude, W. (2008). Conflict, disasters and no jobs: Reasons for international migration from Sub-Saharan Africa (Research paper). United Nations University World Institute for Development Economics Research.

Okeja, U. (2017a). The moral challenge of expatriate employment in developing countries. Etikk i praksisNordic Journal of Applied Ethics, 11(2), 65-77.

Okeja, U. (2017b). Reverse migration, brain drain and global justice. South African Journal of Philosophy, 36(1), 133-143.

Oltra, V., Bonache, J., \& Brewster, C. (2013). A new framework for understanding inequalities between expatriates and host country nationals. Journal of Business Ethics, 115(2), 291-310. https://doi.org/http://dx.doi.org/10.1007/s10551-012-1397-0

O'Reilly, K. (2012). International migration and social theory. Palgrave Macmillan.

Pilati, M., Sheikh, H., Sperotti, F., \& Tilly, C. (2015). Introduction: Understanding the causes, consequences and possible responses to global migration flows In M. Pilati, H. Sheikh, F. Sperotti, \& C. Tilly (Eds.), How global migration changes the workforce diversity equation (pp. 1-14). Cambridge Scholars Publishing.

Portes, A. (2010). Migration and social change: Some conceptual reflections. Journal of ethnic and migration studies, 36(10), 1537-1563.

Portes, A. (2012). Tensions that make a difference: Institutions, interests, and the immigrant drive 1. Sociological Forum, 27(3), 563-578.

Reitz, J. G. (2002). Host societies and the reception of immigrants: Research themes, emerging theories and methodological issues. International Migration Review, 36(4), 1005-1019.

Robinson, R. (2005). Beyond the state-bounded immigrant incorporation regime: Transnational Migrant communities: Their potential contribution to Canada's leadership role and influence in a globalized world. North-South Institute.

Scheible, D. H. (2015). Expatriation as an element of diversity management. Sociology Study, 5(5), 347-353.

Scheible, D. H. (2017). The role of expatriation in the context of managing diversity in international organizations. Interculture Journal: Online-Zeitschrift für interkulturelle Studien, 17(27/28), 87-96.

Schiller, N. G. (2009). A global perspective on migration and development. Social Analysis, 53(3), 14-37.

Shrestha, M. B. (2011). Reversing the flow of international migration. International Journal of Social Economics, 38(2), 165-176.

Syed, J., Hazboun, N. G., \& Murray, P. A. (2014). What locals want: Jordanian employees' views on expatriate managers. The International Journal of Human Resource Management, 25(2), 212-233.

Toh, S. M., \& DeNisi, A. S. (2005). A local perspective to expatriate success. Academy of Management Perspectives, 19(1), 132-146.

Tsuda, T. (2012). Whatever happened to simultaneity? Transnational migration theory and dual engagement in sending and receiving countries. Journal of Ethnic and Migration Studies, 38(4), 631-649.

United Nations. (1998). Recommendations on statistics of international migration (Statistical Papers Series M, 58, 1). Department of Economic and Social Affairs, Statistics Division.

Vertovec, S. (2002, 14-15 February). Transnational networks and skilled labour migration. Paper presented at the Ladenburger Diskurs "Migration” Gottlieb Daimler- und Karl Benz-Stiftung, Ladenburg, Germany. 
Wee, R. Y. (2018). Most ethnically diverse countries in the world.

https://www.worldatlas.com/articles/most-ethnically-diverse-countries-in-the-world.html

World Bank. (2006). Global economic prospects economic implications of remittances and migration. http://wwwwds.worldbank.org/servlet/WDSContentServer/WDSP/IB/2005/11/14/000112742 20051114174928 /Rendered/PDF/343200GEP02006.pdf

Xiang, B., \& Lindquist, J. (2014). Migration infrastructure. International Migration Review, 48(1 suppl), 122-148. manuscripts focusing on interdisciplinary research in social change that improves the human condition and moves people, groups, organizations, cultures, and society toward a more positive future. 